\title{
Predicting the Vehicle Performance at an Early Stage of Development Process via Suspension Bushing Design Tool
}

\author{
Sooncheol Park ${ }^{1} \quad$ Yonggwon Jeon $^{1} \quad$ Dae-oh Kang $^{2} \quad$ Min-su Hyun $^{3} \quad$ Seung-jin Heo ${ }^{3}$ \\ ${ }^{1}$ Hyundai Motor Company, Republic of Korea, \{testdrv, yonggwon.jeon \} @ hyundai . com \\ ${ }^{2}$ Institute of Vehicle Engineering, Republic of Korea, bigfive@ivh.com \\ ${ }^{3}$ School of Automotive Engineering, Kookmin University, Republic of Korea, \{ s lay, sj heo\}@kookmin.ac.kr
}

\begin{abstract}
This paper describes a method for verifying vehicle performance when applying a new suspension bushing at the concept phase of vehicle development. At the concept phase, it is difficult to obtain the nonlinear characteristics of the bushing, which plays an important role in the performance of the vehicle. Thus, a tool to design bushing has been developed.

A method that designers can intuitively and easily design a bush is proposed. It combines the results of the developed bushing design tool with a Modelica system model to evaluate $\mathrm{NVH}, \mathrm{R} \& \mathrm{H}$, and durability performance. Designers can create a new bushing using the bushing design tool and check the vehicle performance at an early stage of development process. The developed bushing design tool allows designers to evaluate vehicle performance by reflecting bushing characteristics without actual products.
\end{abstract}

Keywords: suspension bushing, bushing design, vehicle dynamics, parameter identification.

\section{Introduction}

The vehicle development cycle in the automotive industry is getting shorter and shorter. To cope with shorter development cycle, it is important to achieve vehicle performance such as NVH (Noise, Vibration and Harshness), R\&H (Ride and Handling) and durability performance in the concept phase as shown in Fig. 1. Each performance must be designed in harmony with each other. To be able to verify this performance, it must be possible to carry out test without actual vehicles and parts, because tests using actual vehicles and parts are time-consuming, costly and effort-intensive. In other words, a simulation model that can reflect actual phenomena must be constructed in the concept phase.

For the vehicle model, a variety of force elements and material properties are needed. For example, vehicle performance is affected by static stiffness, dynamic stiffness and loss angle of suspension bushing and engine mount, shock absorber properties, boll-join properties and tire properties. Thus, the reliability of the results is determined by the consistency of the force components that make up the model. These components have nonlinear properties and usually can be obtained through component tests. However, it is difficult to obtain physical properties at the concept stage. Also, since there is no actual component, it is difficult to apply it to various characteristics.

In this paper, new characteristics of suspension bushing are determined using a bushing design tool written in-house code. To verify vehicle performance, the results of the bushing design tool and a Modelica system model are used.

\section{Bushing design tool}

Suspension bushing is described briefly. It is explained the bushing design tool for designers. It is included the bushing model, parameter identification, and bushing design method. Based on relevant technology, bushing design tool has been made with in-house code.

\subsection{Suspension bushing}

The suspension components are connected to each other, to the subframe, and to the body structure via rubber bushings. They are a key element in designing desired static and dynamic behavior of suspension system. The dynamic characteristics of a rubber bushing are often very complex and nonlinear because the response is dependent on several variables, such as frequency, amplitude, preload, and temperature.

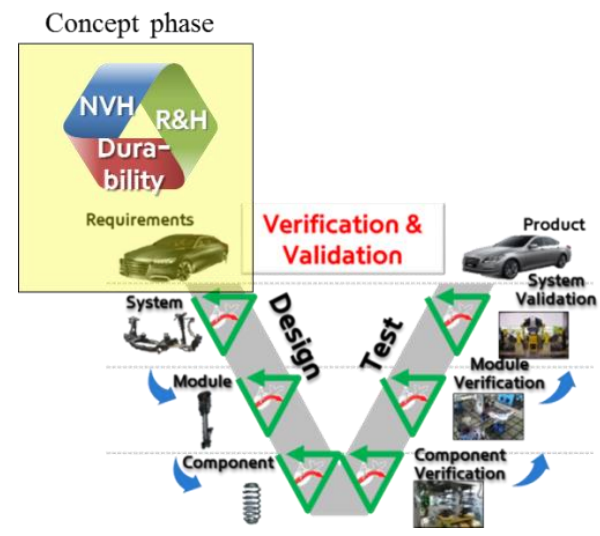

Figure 1. Vehicle development cycle and concept phase. 


\subsection{Bushing model \& Parameter identification}

A generalized linear elastic viscoelastic elastoplastic model (generalized Maxwell model) is used as a bushing model. It contains several Maxwell elements and frictional elements as shown in Fig. 2. Each element is called as a cell. This component model is able to model both frequency and amplitude dependent rubber behavior such as dynamic stiffness and phase angle.

The bushing model has several unknown parameters. In order to obtain the unknown parameters, optimization algorithm is applied to the bushing model. Optimization is searching process to find a minimum value for a certain function which expresses the sum of the relative error compared to the target value.

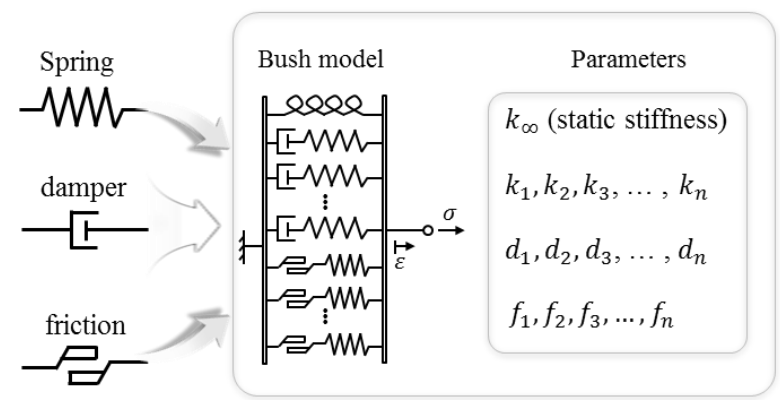

Figure 2. Generalized linear elastic viscoelastic elastoplastic model with n-cells and its parameters.

\subsection{Bushing design method}

The interface of the developed bushing design tool is shown in Fig. 3. It consists of target setup, model setup, optimization, and model parameters as an output.

At the target setup, designers use test data of original bushing as an input of bushing design tool. Next, designers determine the number of cells for the bushing model at the model setup. Then, the bushing design tool proceeds with the parameter identification through an optimization process based on the input test data and the number of cells of the bushing model. It is observed that the optimized results are within $10 \%$ error.

Designers then determine the new bush characteristics which have the desired value based on original bushing model. They modify static and dynamic stiffness curve as shown in Fig. 4 and Fig 5. The bushing design tool calculates the parameters of the model according to the new bushing characteristics as shown in Fig. 6. When verifying vehicle performance, it is used the bushing model parameters from bushing design tool.

\section{Modelica based model}

It is explained how to apply the new bushing characteristics calculated by the bushing design tool to a Modelica system model. A bushing model which has six degrees of freedom is constructed. Vehicle performance is verified by applying the bushing model to the suspension model. Also additional test rigs were constructed.

\subsection{Suspension bushing model}

The unidirectional bushing model was explained in section 2. However, a bushing has six degrees of freedom actually. Therefore, the model for three translational and three rotational directions is constructed as shown in Fig. 7. Each directional model is composed of generalized Maxwell model.

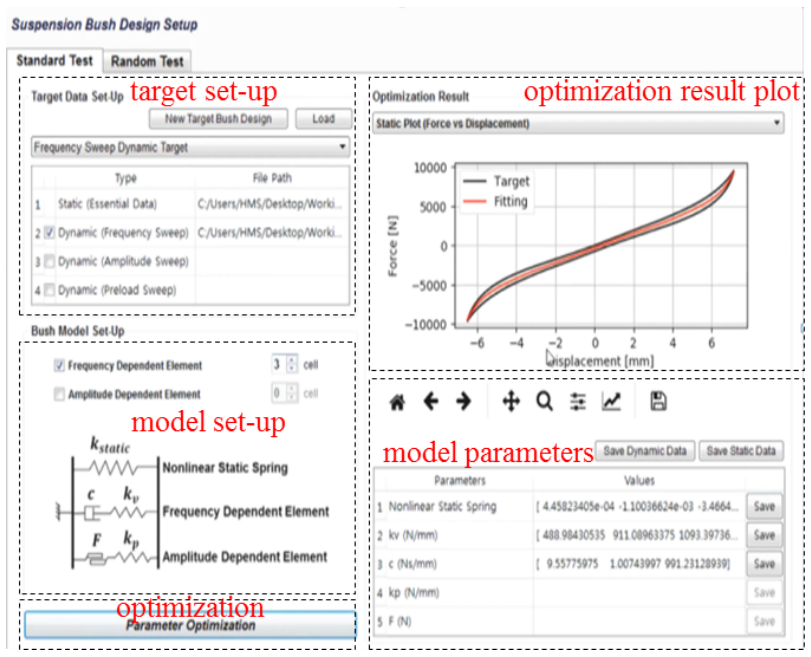

Figure 3. Interface of suspension bushing design tool.
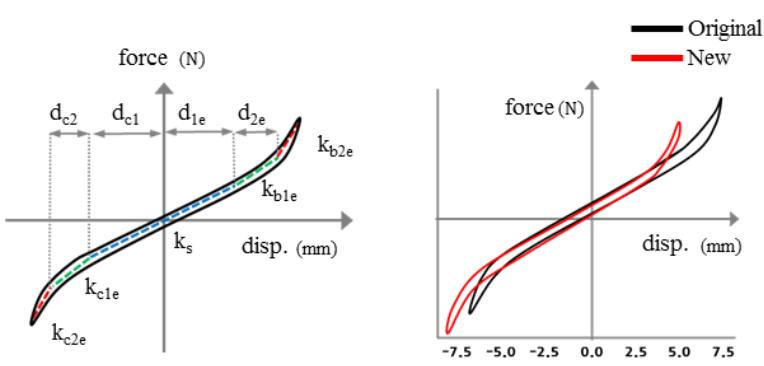

Figure 4. Determination of new static characteristics.

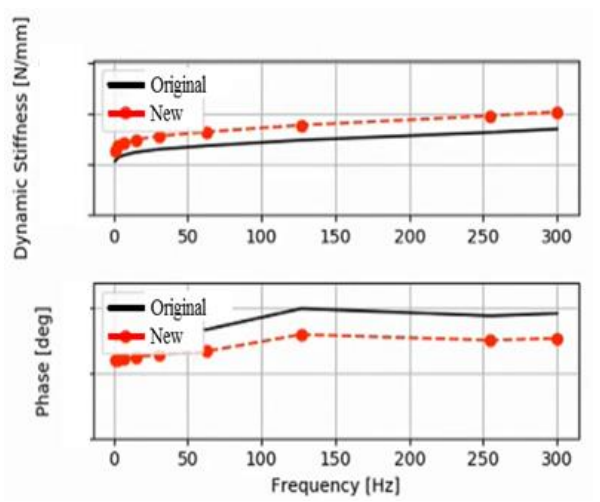

Figure 5. Determination of new dynamic characteristics. 

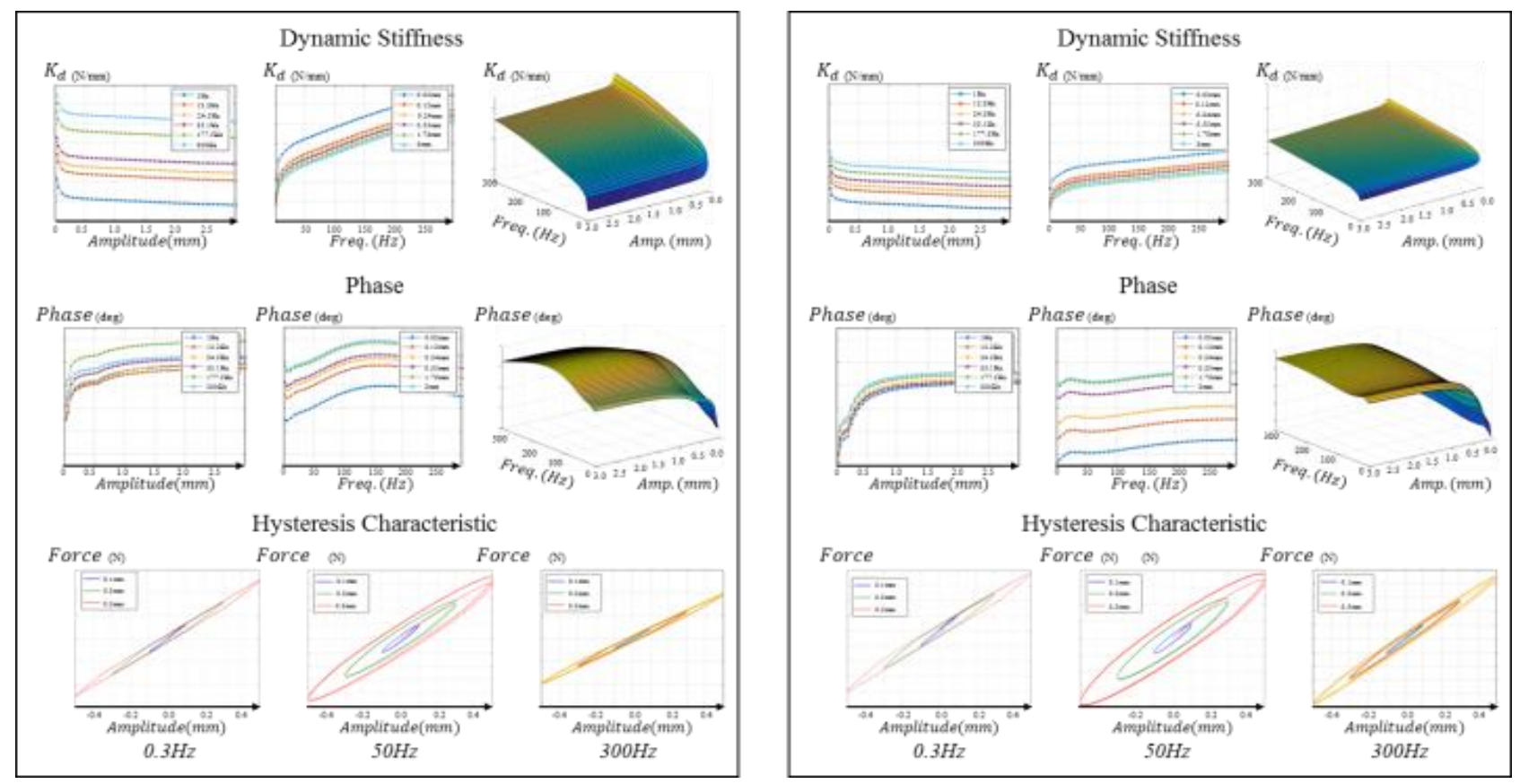

Figure 6. Characteristics of original bushing model (left side) and new bushing model (right side).

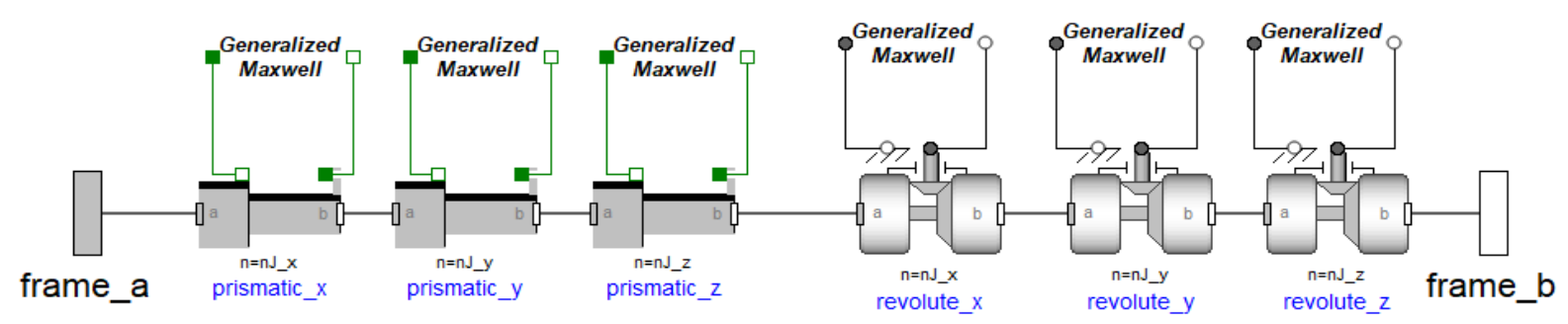

Figure 7. Six degrees of freedom suspension bushing model connected to each link.

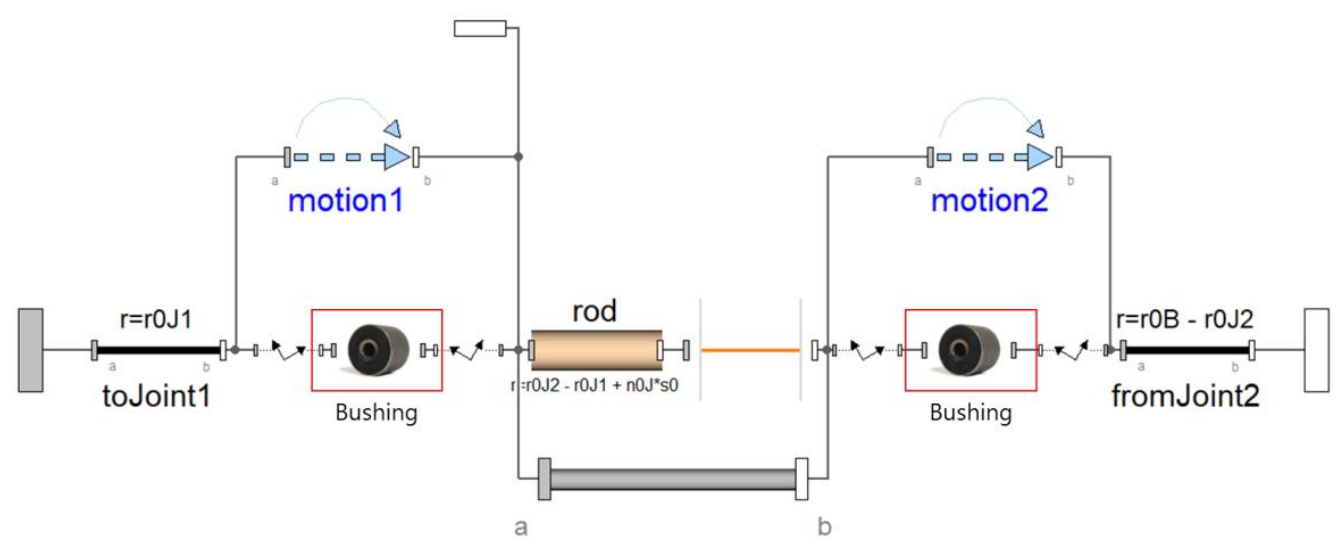

Figure 8. Upper arm and bushing model. 


\subsection{Suspension system model}

The Vehicle Dynamics Library (VDL) of Modelon is applied as a suspension system model. The bushing models that make up the suspension are replaced with the generalized Maxwell model from the KelvinVoight model that is provided as standard. As shown in Fig. 8, the bushing is connected to the arm. Bushings and arms combine with other components to form a linkage model as shown in Fig. 9. The configured linkage model is coupled to the suspension model as shown in Fig. 10.

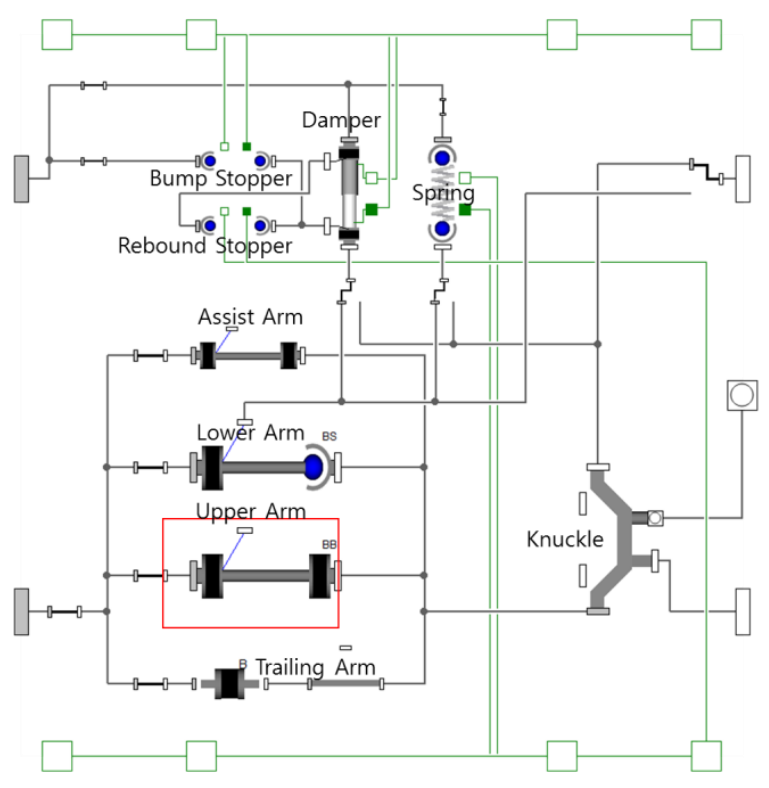

Figure 9. Trailing arm type multilink suspension linkage.

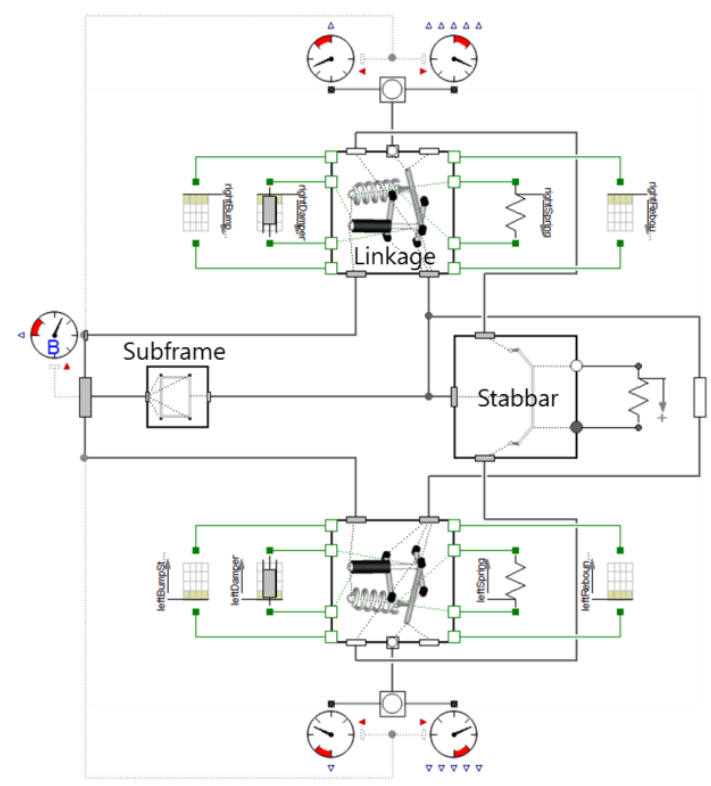

Figure 10. Trailing arm type multilink suspension model.

\section{Simulation}

Using the results of bushing design tool in section 2 and the models mentioned in section 3 , the vehicle performance is evaluated in the view of durability, $\mathrm{NVH}$ and R\&H.

\subsection{Model for Durability and NVH}

In order to verify vehicle performance in the view of durability and NVH, a model is constructed as shown in Fig. 11. The wheel load measured on the Belgian road is used as the input drive signal for the durability test. To verify $\mathrm{NVH}$ performance, white pink noise with a border frequency of $250 \mathrm{~Hz}$ and a cutoff frequency of $300 \mathrm{~Hz}$ is given as vertical displacement.

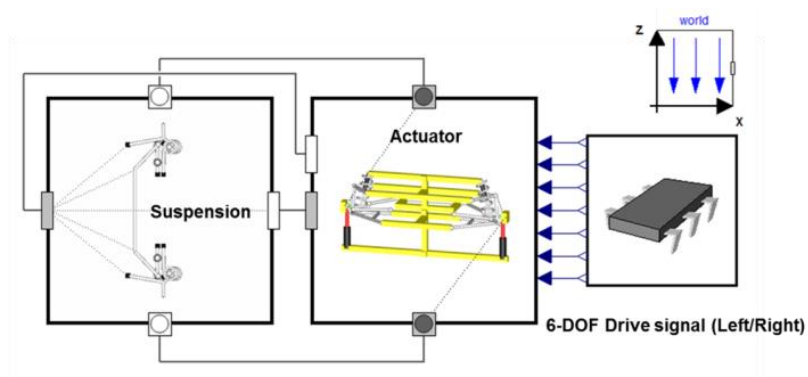

Figure 11. Trailing arm type multilink suspension linkage.

\subsection{Model for R\&H}

For the step steer test, the model is constructed as shown in Fig. 12. Test conditions are applied based on ISO-7401 standard. A constant velocity value and the ramp type steering value with duration time of $0.15 \mathrm{sec}$ are used as inputs.

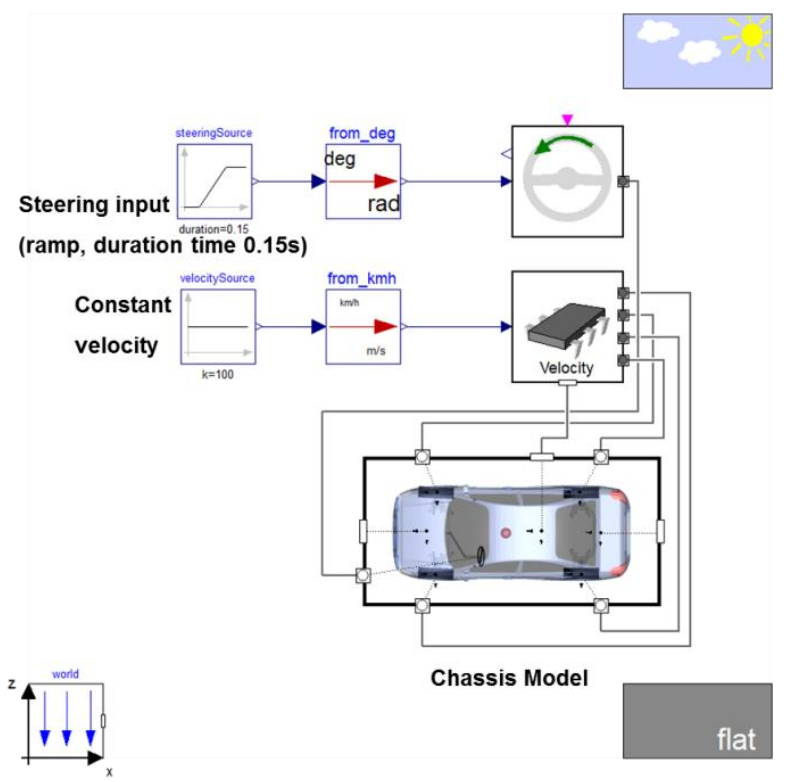

Figure 12. Step steer test model. 
For the constant radius cornering test, the model is constructed as shown in Fig. 13. Test conditions are applied based on ISO-4138 standard. Closed loop steering input and velocity profile with duration time $600 \mathrm{sec}$ are used as input values to make a turn radius of $50 \mathrm{~m}$.

For the four-post test, the model is constructed as shown in Fig. 14. ISO C-class road surface profile is used as drive signal.

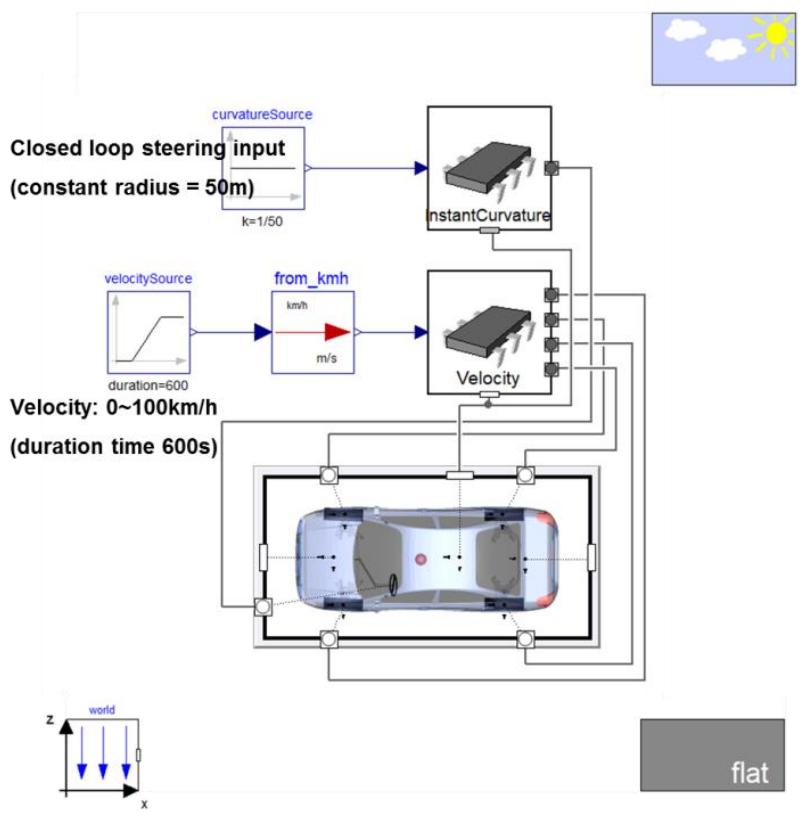

Figure 13. Constant radius cornering test model.

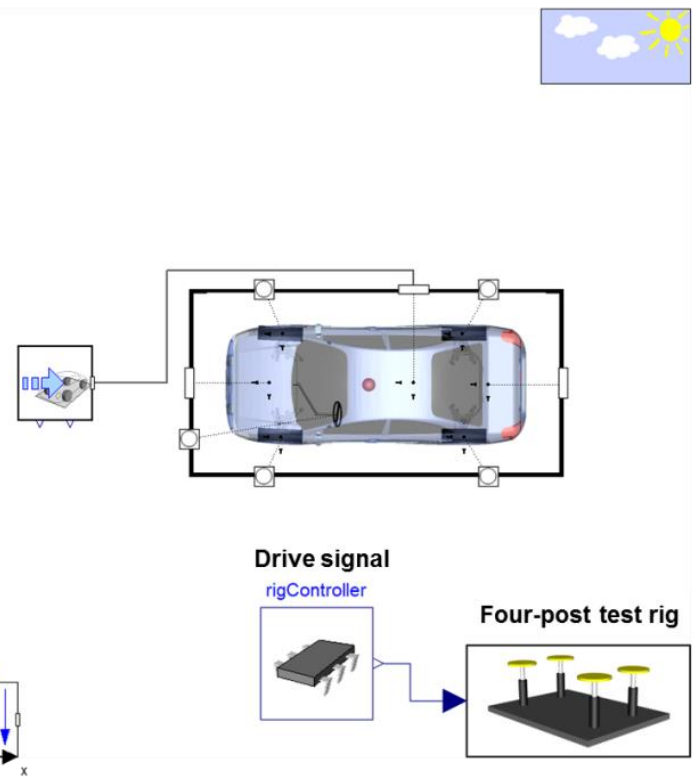

Figure 14. Four-post test model.

\subsection{Simulation results}

These are the simulation results while changing the characteristics of the suspension bushings such as lower arm bushing, upper arm bushing, assist arm bushing and trailing arm bushing.

For each result, the blue line is the result of the original bushing. The red line indicates the larger dynamic stiffness value than the original one. The green line indicates the smaller dynamic stiffness value than the original one.

\subsubsection{Durability and NVH}

In the view of durability performance, the change in load applied to each bushing can be confirmed from the values of the time domain and the power spectral density of the frequency domain as shown in Fig. 15.
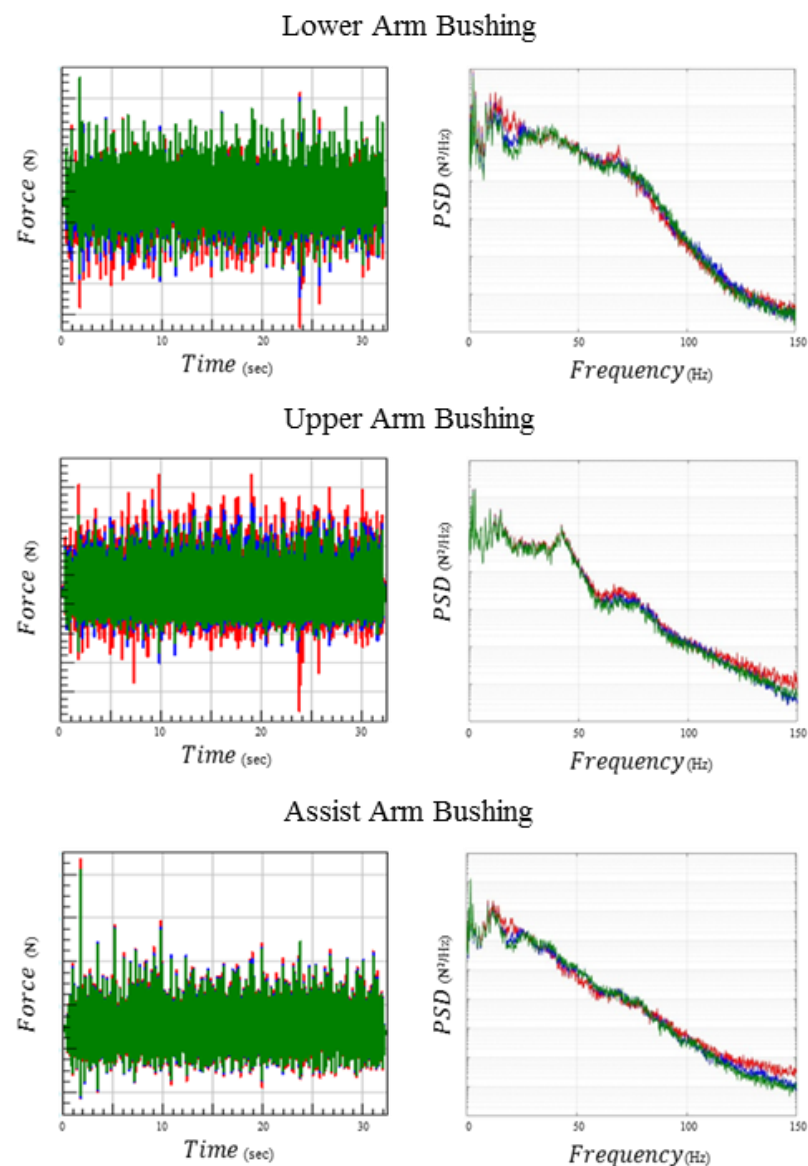

Trailing Arm Bushing
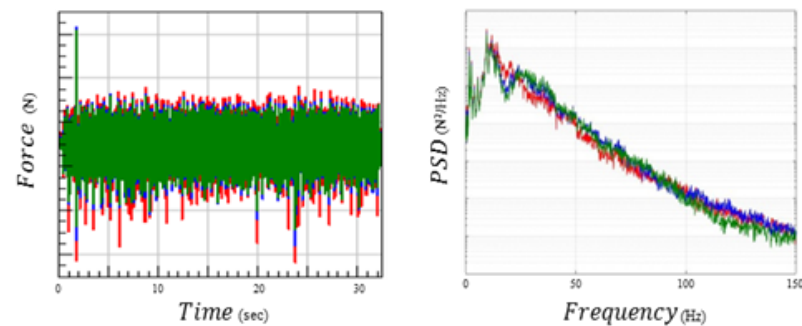

Figure 15. Durability performance 
Predicting the Vehicle Performance at an Early Stage of Development Process via Suspension Bushing Design Tool

Similarly, the change of the load of each bushing and the acceleration of the vehicle body can be checked in the view of NVH as shown in Fig. 16.

\subsubsection{R\&H}

Fig. 17 depicts constant cornering test and step steer test results. The performance of handling can be confirmed by the changed values of the understeer gradient, response time and overshoot value as the new bushing is applied. From Fig. 18, ride performance can be checked through vehicle body acceleration analysis.
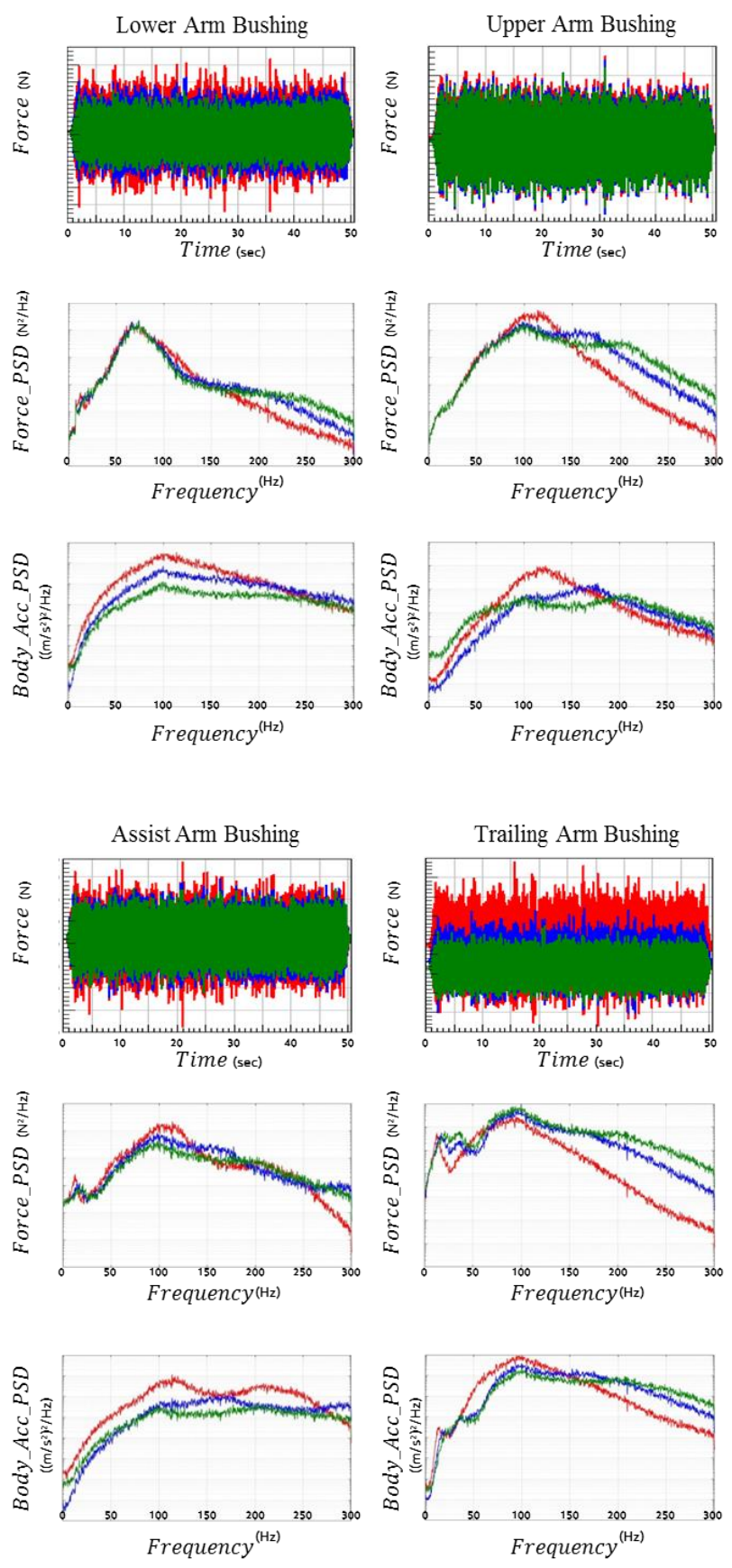

Figure 16. NVH performance

\section{Constant Radius Cornering}

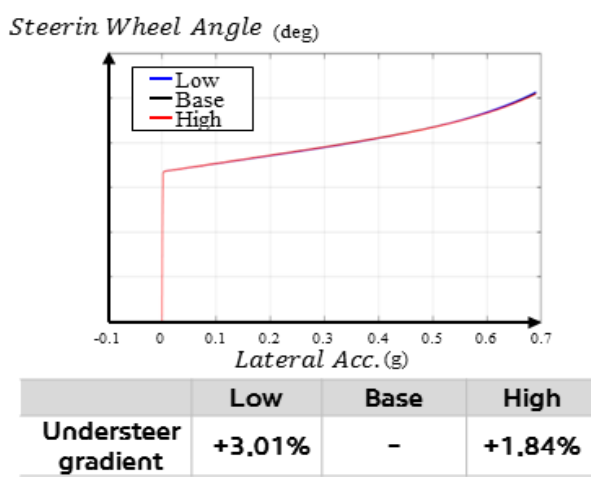

Step Steer

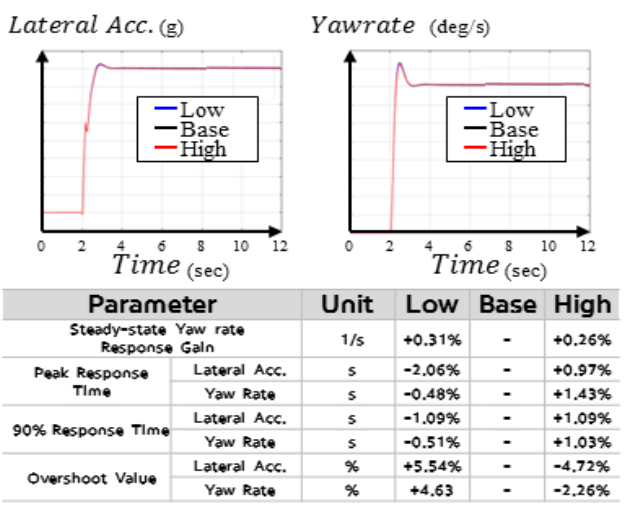

Figure 17. Handling performance.
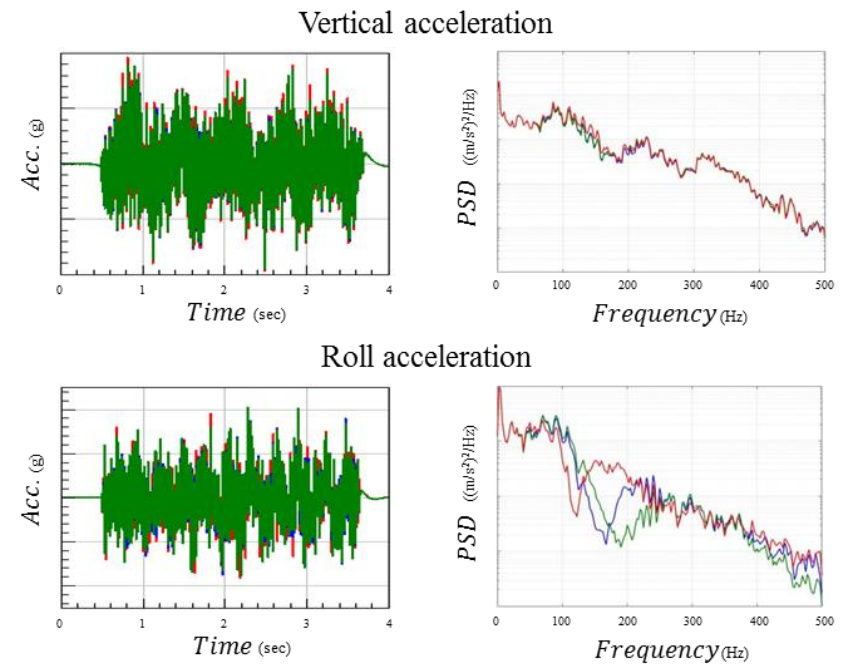

Pitch acceleration
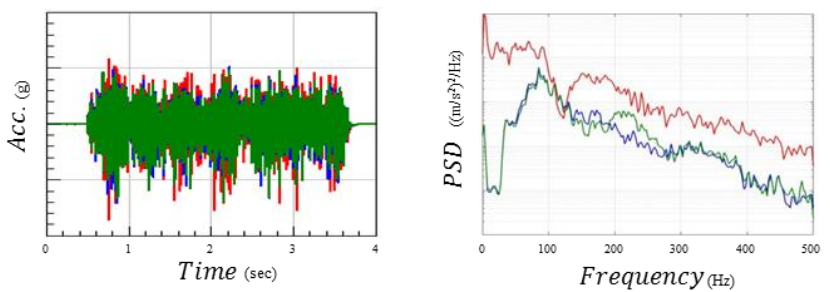

Figure 18. Ride performance. 


\section{Conclusion}

In this paper, vehicle performance is verified at the concept stage by using the results of the developed bushing design tool and a Modelica system model. Designers can make various bushing characteristics in an intuitive and easy way using the bushing design tool. First, designers use original model's test data as an input of bushing design tool and determine the number of cells for the bushing model. The bushing design tool proceeds with the parameter identification through an optimization process based on the input test data and the number of cells of the model. The designers then determine the new bushing characteristics to get the desired static and dynamic characteristics in the original characteristics. The bushing design tool calculates the parameters of the bushing model according to the bushing characteristics changed to the result value. From simulation results, the vehicle performance is changed according to the characteristics of the suspension bushing. The designers can confirm the vehicle performance at the concept stage if the bushing, determined by the designers, is applied.

The optimum bushing specification will be determined by optimizing the vehicle performance with the bushing characteristics in the future.

\section{References}

Fredrik Karlsson and Anders Persson. Modelling non-linear dynamics of rubber bushings -Parameter identification and validation . Master's thesis, 2003.

Jun Nakahara, Koji Yamzaki, Yusuke Otaki. Rubber bushing model for vehicle dynamics performance development that considers amplitude and frequency dependency. SAE Int. J. Commer:Veh, 8(1):117-125, 2015. doi: 10.4271/2015-011579.

Kai Sedlaczek, Sven Dronka and Jochen Rauh. Advanced modular modelling of rubber bushings for vehicle simulations. Vehicle system dynamics 49(5):741-759, 2011. doi: 10.1080/00423111003739806.

Michael Fleps-Dezasse Jakub Tobolárr Johannes Pitzer. Modelling and parameter identification of a semi-active vehicle damper. Proceedings of the 10th International ModelicaConference, 2014. doi: 10.3384/ECP14096283. 
Predicting the Vehicle Performance at an Early Stage of Development Process via Suspension Bushing Design Tool 